Disponível em

http://www.anpad.org.br/rac

RAC, Curitiba, v. 14, n. 2, art. 2,

pp. 212-228, Mar./Abr. 2010

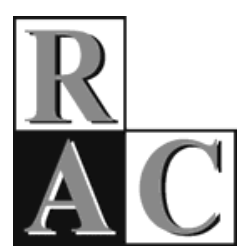

\title{
Quando Descentralizar é Concentrar Poder: o Papel do Governo Estadual na Experiência Catarinense
}

\section{When Decentralize is to Concentrate Power: State Government Role in the Catarinense Experience}

Eliane Salete Filippim * Doutora em Engenharia de Produção pela UFSC. Professora na Unoesc, Joaçaba/SC, Brasil.

Fernando Luiz Abrucio Doutor em Ciência Política pela USP. Professor da FGV/SP, São Paulo/SP, Brasil.

* Endereço: Eliane Salete Filippim

Rua Paulo Germano Liedke, 272, Bairro Flor da Serra, Joaçaba/SC, 89600-000. E-mail: eliane.filippim@unoesc.edu.br

Copyright (C) 2010 RAC. Todos os direitos, inclusive de tradução, são reservados. É permitido citar parte de artigos sem autorização prévia desde que seja identificada a fonte. 


\title{
RESUMO
}

Uma das principais marcas da Constituição do Brasil de 1988 foi a ênfase dada à descentralização, tomada como positiva para a democratização. No entanto há diferentes formas de implementar o processo descentralizador. Este artigo tem como objetivo descrever e analisar a experiência de descentralização pela via do governo estadual em Santa Catarina, iniciada em 2003. Quanto aos procedimentos metodológicos, a pesquisa se insere numa abordagem qualitativa de reconstrução histórico-institucional, por meio de um estudo de caso. Para a coleta de dados foram utilizados multimétodos. Foram realizadas entrevistas abertas com atores diretamente envolvidos no processo de descentralização, aplicando-se questionário dirigido às 36 Secretarias de Desenvolvimento Regionais [SDRs] e aos 24 Fóruns de Desenvolvimento. Foi realizada ainda a análise de documentos e a observação dos pesquisadores em reuniões, tanto de SDRs quanto de Fóruns de Desenvolvimento. O fenômeno estudado neste trabalho revela como a descentralização, ao contrário do esperado, pode ser usada como mecanismo de concentração de poder. Isto porque se, por um lado, a atuação do governo catarinense é propagada como maneira de se aproximar do cidadão, por outro construiu-se aí uma estratégia político-partidária de consolidação no poder da atual coalizão política dominante no Estado.

Palavras-chave: descentralização; gestão pública; redes de articulação regional.

\begin{abstract}
One of the principal points of the 1988 Brazilian Constitution was the emphasis placed on decentralization. However, there are different forms of implementing the decentralization process. The aim of this article is to describe and analyze the decentralization experience by way of the state government in Santa Catarina, beginning in 2003. As for the methodological procedures, the study is inserted in a qualitative approach of historical-institutional reconstruction, through a case study. For data collection multi-methods were used. Interviews were conducted with actors who were closely involved in the decentralization process. A questionnaire was forwarded to 36 Regional Development Secretariats [RDS] and 24 Development Forums. Documents were also collected through analysis and the observations of researchers at meetings, both of the RDSs and the Development Forums. The phenomenon studied in this work shows how decentralization, contrary to what was expected, can be used as a power concentration mechanism. The reason for this is that, on the one hand, the actions of the government of Santa Catarina are a way of drawing closer to the people, and on the other hand, a party policy strategy to consolidate the power of the current coalition that is dominant in the State.
\end{abstract}

Key words: decentralization; public management; regional articulation nets. 


\section{INTRODUÇÃO}

O conceito de descentralização utilizado no Brasil supõe, pelo menos desde a redemocratização, que sua implementação leve a maior autonomia dos governos locais. Na visão mais otimista sobre este processo, descentralizar significaria maior democracia e eficiência governamental. Numa posição mais crítica, alguns autores realçam que repassar o poder às municipalidades pode gerar novas formas de clientelismo e transferir encargos sem que os municípios estejam preparados para produzir as políticas públicas (Abrucio \& Soares, 2001; Arretche, 1996). Em ambos os casos, a literatura recente deixou de tratar de processos descentralizadores que escondem forte estratégia centralizadora.

É sobre esta questão que o presente artigo vai debruçar-se: o conflito entre um modelo descentralizador proposto pelo governo estadual catarinense, consolidado a partir de 2003, e outro paradigma de descentralização produzido pelos municípios e pelas redes de articulação regional, presentes no Estado há décadas. Para entender a singularidade deste caso, é preciso entender, primeiramente, que a descentralização se insere no Brasil em contexto maior: o funcionamento do modelo federativo, no qual podem ser colocados em prática simultaneamente diversos modelos de autonomia e de coordenação entre os níveis de governo.

A variedade de experiências descentralizantes pode ser explicada, ainda, pelo cenário político resultante do confronto de forças em cada Estado. Este cenário condiciona a escolha do modelo de gestão, que, por sua vez, configura as instituições que conduzem e efetivam as mudanças rumo à descentralização. Neste sentido, o caso catarinense, objeto deste estudo, parece ser eloquente para o entendimento da complexidade de propostas de descentralização, seja qual for o modelo adotado.

Este artigo trata, portanto, do seguinte tema: uma unidade federativa (Santa Catarina) com forte tradição de articulação associativista de base territorial passa, desde 2003, por um processo de descentralização para o desenvolvimento regional, implantado pelo governo do Estado. Este fenômeno no qual uma proposta estado-cêntrica de articulação regional se sobrepôs a outra, de organização de redes regionais de cooperação, nascidas da iniciativa da sociedade civil e largamente fundamentadas em associativismo, é pouco comum na federação brasileira. Normalmente, o que se vê são experiências em que o centralismo permaneceu forte, mesmo após a descentralização, ou então modelos de reversão da tendência mais centralizadora, com o fortalecimento dos grupos regionais e/ou municipalistas. Sob esta ótica, o estudo em questão revela outro caminho intergovernamental, virando de ponta-cabeça os modelos analíticos e normativos vigentes. Trata-se de um caso extremo, algo que deve ser pesquisado para realçar os limites das explicações hegemônicas e abrir espaço a novas interpretações e, sobretudo, investigações. Considera-se, ademais, relevante estudar a experiência de descentralização no âmbito dos Estados já que "os locais por excelência do aprendizado republicano são o poder local e o nível estadual, uma vez que tanto a classe política como os cidadãos têm seus processos de socialização política realizados nos níveis subnacionais de governo” (Abrucio, 1998 como citado em Diba, 2004, p. 36).

A questão orientadora do debate é se a experiência catarinense consiste de fato em descentralização para o desenvolvimento, tal como proposta pelos seus promotores - notadamente o governo do Estado - ou se produziu uma desconcentração administrativa que se sobrepôs às redes de articulação locais/regionais pré-existentes no Estado. Coloca-se, portanto, um desafio: como efetivar um processo de descentralização pela via da articulação regional, salvaguardando tanto a autonomia quanto a interdependência dos envolvidos (Estado, Municípios, Regiões)?

Quanto à abordagem aqui adotada, este estudo se insere no contexto da pesquisa qualitativa, centrada na reconstrução histórico-institucional. Em relação à estratégia metodológica, optou-se pelo estudo de caso. De acordo com Yin (2001), este método de caso é apropriado para pesquisar eventos atuais e quando o fenômeno a ser pesquisado, além de apresentar certa singularidade, caracteriza-se pela presença de inúmeras variáveis, cuja instabilidade de ocorrência é grande. Soma-se a isso o fato 
de se tratar de um caso extremo, como dito anteriormente, cuja qualidade maior não é produzir grandes generalizações, mas matizar as já existentes, trazendo novas perguntas à literatura.

Este estudo, ademais, assume relevância por ser forma duplamente exemplar. Por um lado, é caso de articulação regional numa federação em que há pouca coordenação intergovernamental (Abrucio \& Soares, 2001) e, por outro, desenvolve-se em ambiente em que a descentralização é tanto anterior ao restante do país, quanto diferente, pois se deu pelo associativismo local e não por iniciativa dos governos federal ou estadual.

\section{DEFINIÇÃO DO DESENHO DE PESQUISA}

A iniciativa da sociedade civil catarinense fez surgir, na década de 1960, a cooperação regional, por meio da organização de redes de articulação de base territorial, que congregavam entidades públicas e privadas com o intuito de fomentar o desenvolvimento. No início dos anos 1990, estas redes tomaram a forma de fóruns e agências de desenvolvimento: todas as sub-regiões de Santa Catarina colocaram em funcionamento estes mecanismos de cooperação regional. No entanto, no ano de 2003, por força de lei, o governo de SC estabeleceu as Secretarias de Desenvolvimento Regional [SDRs] que, além de assumirem boa parte das funções das secretarias centrais/setoriais, foram incumbidas de promover o desenvolvimento de suas regiões. Este movimento do governo do Estado apresenta uma dualidade: se por um lado caminhou na direção da descentralização pela via da articulação regional, por outro desconsiderou a atuação anterior dos Fóruns e Agências que tinham propósitos muito similares aos das SDRs. Além de desconsiderar a experiência anterior, a área geográfica das SDRs não respeitou a dos antigos fóruns de desenvolvimento e/ou das associações de municípios, rede de cooperação municipalista presente no Estado desde 1961.

Em poucas palavras, o problema de pesquisa que orienta este trabalho diz respeito ao conflito entre estes dois modelos descentralizadores: o nascido nos municípios e redes locais de articulação da sociedade civil, e o originado do governador Luiz Henrique, montado em nome da regionalização e da aproximação do governo estadual aos cidadãos.

Diante desta problemática, para atender os contornos da pesquisa qualitativa, foram adotados multimétodos: a entrevista, o questionário, a análise de documentos e a observação de campo. Para tanto, foram definidos os eixos de análise (Tabela 1) e os seus indicadores. Foram feitas 26 entrevistas abertas com atores envolvidos no processo de descentralização no Estado de SC, quais sejam, agentes políticos ligados ao governo estadual e da oposição, conselheiros de desenvolvimento regional, servidores públicos das SDRs e colaboradores do governo Luiz Henrique da Silveira, que idealizaram a descentralização em Santa Catarina. Nestas entrevistas buscou-se conhecer a origem, as características e as visões que nortearam a implantação (e a oposição) deste processo. Na análise os entrevistados foram citados como E (Entrevistados), seguidos do número de controle, para garantir a confidencialidade.

Além das entrevistas abertas, foram enviados questionários às 36 SDRs e aos 24 Fóruns/Agências de Desenvolvimento, num total de 60 questionários enviados, via correio eletrônico, seguidos de telefonema de reforço, solicitando o envio das respostas. Deste total, retornaram 19 respondidos, sendo 14 das SDRs e 5 dos fóruns/agências. Credita-se à baixa quantidade de respostas dos fóruns/agências a paralisação das atividades deles após a implantação das SDRs pelo governo do Estado em 2003. Este fato reforça um dos argumentos deste estudo: a criação das SDRs enfraqueceu a iniciativa associativista que existia em SC de articulação territorial pelo desenvolvimento.

Outros dados foram obtidos por meio da análise de documentos do governo estadual (relatórios, pronunciamentos oficiais, manuais, etc); da análise de legislação específica; dos sites das SDRs e das organizações de interesse para a pesquisa (secretarias centrais, associações de municípios, fóruns regionais, Federação Catarinense de Municípios [FECAM] etc.) e pela observação direta dos 
pesquisadores de duas reuniões nas SDRs e duas reuniões de fóruns de desenvolvimento regional. Tanto o roteiro da entrevista, quanto o questionário e as observações foram norteados pelos eixos de análise e seus indicadores (Tabela 1).

Tabela 1

\section{Eixos de Análise e Indicadores}

\begin{tabular}{ll}
\hline Eixos de análise & Indicadores \\
\hline O Contexto do fenômeno em estudo & . contexto socieconômico; \\
& . contexto cultural e tradição associativista; \\
Características da descentralização & . o foco da descentralização; \\
& . ordenamentos legais e processo de implantação; \\
& . relações governo/sociedade; \\
& . a visão de mentores e opositores. \\
& . coalizões político-eleitorais; \\
Sustentação política & . atuação do governo. \\
Resultados & . orçamento/alocação de recursos; \\
& - programas/projetos/ações; \\
& . poder decisório das regiões. \\
Participação social & . a participação no processo de descentralização; \\
& . mobilização de atores; \\
& . a composição de Conselhos regionais. \\
Apoio Institucional e avaliação & . ações integradas e parcerias; \\
\end{tabular}

Nota. Fonte: elaborado pelos autores.

\section{DESCENTRALIZAÇÃO E RELAÇÕES INTERGOVENAMENTAIS}

Esta seção apresenta os temas que nortearam este estudo, basicamente o federalismo, a descentralização e as relações intergovernamentais. O termo federalismo alcança, na literatura, uma diversidade de conceituação, de caracterização e de práticas nas mais diferentes federações, conforme afirma Souza (1998). Neste trabalho, parte-se da definição de Elazar (1987 como citado em Abrucio \& Soares, 2001, p. 34), quando afirma que

em essência, um arranjo federal é uma parceria, estabelecida e regulada por um pacto, cujas conexões internas refletem um tipo especial de divisão de poder entre parceiros, baseada no reconhecimento mútuo da integridade de cada um no esforço de favorecer uma unidade especial entre eles.

Abrucio e Soares (2001) apontam que a conformação de uma situação federalista ocorre quando está presente tanto a heterogeneidade (territorial, lingüística, étnica, socioeconômica, cultural e política) quanto um projeto em prol da unidade na diversidade. Neste sentido, a Federação possui, para estes autores, cinco características gerais: "um modelo intrinsecamente contratual; a soberania compartilhada; a compatibilização entre autonomia e interdependência; instituições que procuram equilibrar as regras da maioria com os direitos da minoria; e ... relações intergovernamentais" (Abrucio \& Soares, 2001, p. 33).

Considerando, portanto, que o federalismo engendra uma tensão entre interdependência e autonomia, torna-se fundamental discutir a questão da descentralização, uma vez que a "existência de 
um sistema federal implica cooperação política e financeira entre o governo federal e as demais esferas da Federação” (Souza, 1998, p. 3). Dentre as inúmeras formas de perceber a descentralização, algumas características parecem repetir-se na literatura, tais como: a visão de que a descentralização favorece a aproximação do governo com o cidadão; contribui para a preservação de identidades locais; fomenta o surgimento de parcerias, ações integradas e articulação de atores; propicia ao cidadão maior participação decisória e maior controle das ações dos governos (Arretche, 2000; Farah, 2001; Tendler, 1998; Tobar, 1991). Na tentativa de uma caracterização de descentralização, ela é entendida, neste trabalho, como processo político que resulta em transferência orgânica e organizada e/ou conquista de autonomia fiscal e de gestão de políticas e autonomia em termos de poder decisório, sendo diferente, portanto, da mera delegação de funções administrativas (Abrucio \& Soares, 2001; Rodden, 2005).

A Constituição de 1988 favoreceu, nos seus ordenamentos, a descentralização na distribuição dos recursos tributários e do poder político no Brasil (Souza, 1998). No pós-Constituição, “a autoridade política de cada nível de governo é soberana e independente das demais. Diferentemente de outros países, os municípios brasileiros foram declarados entre federativos autônomos, o que implica que um prefeito é autoridade soberana em sua circunscrição" (Arretche, 2000, p. 4). Todavia, os resultados práticos desta descentralização ainda estão longe de configurar uma significativa autonomia decisória no âmbito subnacional, notadamente na maior parte dos municípios.

Uma saída à visão municipalista autárquica da descentralização é a proposta de redes de articulação regional. Ela também se constitui num contraponto à ação centralizada do governo estadual, incorporando não só os municípios e as regiões dentro das unidades federativas, como também outras formas de articulação e cooperação regional entre atores públicos e privados. Portanto, descentralização requer novos padrões de governança local capaz de fomentar e coordenar a cooperação regional.

Embora a descentralização tenha este apelo à maior autonomia do poder local, à articulação de atores regionais e ao controle mais efetivo do cidadão das ações governamentais, não há garantia alguma de que uma proposta de descentralização supere, por si só, o clientelismo, a corrupção, a perda de capacidade regulatória e de formulação de políticas públicas pelo governo central, além de poder atuar como elemento facilitador do acirramento de disparidades regionais (Arretche, 1996).

As estratégias utilizadas pela União e/ou Estados para que os municípios aderissem à descentralização também não alijaram as práticas de cooptação patrimonialista. Não raro os prefeitos e as lideranças regionais vislumbram muito bem os benefícios políticos de oferecer localmente serviços públicos antes centralizados. Este vislumbre representa um poderoso incentivo à municipalização e à regionalização (Arretche, 2000). Contudo nem sempre os municípios e regiões alcançam capacidade administrativa, capacidade técnica instalada, recursos técnicos, equipamentos, recursos humanos e conhecimento especializado necessários à descentralização, carecendo da ajuda expressa de níveis superiores de governo, a fim de modernizarem sua estrutura e seus modelos de gestão. Neste sentido, torna-se necessário "abandonar a falsa e estéril dicotomia entre centralização e descentralização" (Abrucio \& Soares, 2001, p. 15), e centrar o foco na democratização das relações intergovernamentais.

Para fechar a argumentação desta seção, é preciso discutir a diferença conceitual e operacional entre descentralização e desconcentração. Tobar (1991) aponta para um distanciamento qualitativo entre as duas categorias. Enquanto a descentralização implica redistribuição do poder, a desconcentração é a delegação de competência sem, necessariamente, o deslocamento do poder decisório. A desconcentração significa um "conjunto de procedimentos funcionais para a racionalização, modernização e reprodução ampliada do sistema a modificar” (Tobar, 1991, p. 5). Neste sentido, a adoção da descentralização ou da desconcentração produzirão diferentes resultados na sua implementação. Como veremos, o caso catarinense, embora carregue o nome descentralização no seu projeto, está mais próximo de uma desconcentração: no caso, reverteu-se um processo prévio de descentralização.

A descentralização, entendida como estratégia para promover o desenvolvimento regional, como parece ser a intenção do governo estadual catarinense, requer uma análise da perspectiva da 
regionalização do desenvolvimento. Hoje, há o reconhecimento do papel desempenhado pela região, vista como espaço de integração entre atores sociais que propicia o favorecimento da emergência de dinâmicas coletivas de desenvolvimento integrado (Becattini, 2002). A definição objetiva de região depende da visão dos atores sociais e é amplamente variável, podendo ser as suas fronteiras mutáveis de acordo com os mais diversos interesses em jogo. A demarcação territorial das atuais SDRs foi construída de acordo com os interesses das lideranças regionais, particularmente eleitorais, raramente em continuidade ou alinhadas com as redes de cooperação previamente existentes nestes territórios.

O caso de Santa Catarina revela contradições em relação ao que as teorias de mobilização social e institucionalização política apontam como esperado. Santa Catarina teria as condições ideais para a descentralização participativa, uma vez que conta com uma herança associativa visível, com base num intermunicipalismo autônomo, que não tem paralelo na história dos outros Estados membros. Contudo, embora o processo seja recente e pouco avaliado, pode-se perceber, pelos resultados desta pesquisa que, apesar da tradição associativista, a participação social no processo descentralização, bem como das redes municipalistas, ainda é incipiente, predominando fortemente a atuação indutora do governo estadual.

\section{A EXPERIÊNCIA de SANTA CATARINA: O ConteXto do Fenômeno em Estudo}

Neste bloco, procura-se caracterizar o contexto socioeconômico catarinense que contribuiu para a emergência da articulação regional e para o surgimento da reforma administrativa ocorrida em Santa Catarina [SC] a partir de 2003.

\section{Contexto Socioeconômico}

O Estado de Santa Catarina situa-se na região Sul do Brasil e conta com uma área 95.346,181 km²; sua população é de 5.866.252 habitantes. Contudo, segundo o Instituto Brasileiro de Geografia e Estatística [IBGE], há uma tendência de redução no ritmo de crescimento populacional. Além deste fator, ocorre intenso processo de litoralização. A falta de emprego e oportunidade para os jovens tem feito com que algumas regiões, sobretudo do Oeste Catarinense, tenham diminuído sua população. As regiões do interior do Estado, especialmente o Oeste, sempre se ressentiram do insulamento da capital catarinense. Este ressentimento tem produzido tensões entre centralização-descentralização e contribui para a escolha dos estilos de desenvolvimento regional.

Tabela 2

Comparativo Brasil/Santa Catarina

\begin{tabular}{lcccc}
\cline { 2 - 5 } & População & PIB per capita & IDH & Área \\
\hline Brasil & 191.791 .000 & $\mathrm{R} \$ 12.436,75$ & 0,766 & $8.514 .876,60 \mathrm{~km} 2$ \\
Santa Catarina & 5.866 .252 & $\mathrm{R} \$ 14.539,00$ & 0,822 & $95.346,2 \mathrm{~km}^{2}$ \\
\hline
\end{tabular}

Nota. Fonte: IBGE (2007).

De forma mais institucionalizada, o planejamento governamental em SC teve início em 1955 pelo Plano de Obras e Equipamentos [POE], substituído, em 1961, pelo Plano de Metas do Governo [PLAMEG], que funcionou, por cinco gestões seguidas, como instrumento indutor do crescimento econômico do Estado. O Plameg produziu resultados expressivos na economia catarinense, especialmente na dácada de 70, quando o PIB do Estado praticamente triplicou (Birkner, 2006). 
Os planos de governo subseqüentes tiveram no Plameg sua fonte de inspriação. Contudo percebe-se que o modelo de crescimento, via planificação governamental, nos moldes do Plameg, é percebido como esgotado pelos participantes da coligação que atualmente governa SC: "o modelo catarinense de desenvolvimento implementado pelo PLAMEG está totalmente exaurido” (E8). É possível que a proposição das SDRs pelo governo do Estado em 2002 tenha nesta percepção uma de suas motivações.

\section{Contexto Cultural e a Tradição Associativista}

A matriz etnicocultural catarinense é bastante diversificada. O Estado, inicialmente habitado por distintos grupos indígenas que, miscigenados, deram origem ao caboclo, foi colonizado majoritariamente por imigrantes europeus. Esta diversidade na sua formação faz com que o Estado de SC tenha uma pluralidade cultural muito acentuada, resultando em diferentes formas de organização econômica, social e política em cada região. Esta cultura fortemente signatária da colonização européia seria a responsável pelo modelo catarinense de desenvolvimento, que, segundo Hering (1987), se caracteriza pelo voluntarismo e pelo forte espírito empreendedor trazido por estes imigrantes, que lograram promover o crescimento econômico das diferentes regiões, mesmo sem qualquer auxílio do governo do Estado.

O movimento de articulação/cooperação regional fundado na maior participação de atores locais se intensificou nos anos 1990. Dentre essas iniciativas, uma alcançou destaque, pois foi disseminada em todo o território catarinense: os Fóruns de Desenvolvimento Regional. Estes fóruns tiveram sua implantação liderada pelas associações de municípios em parceria com inúmeras entidades públicas e privadas. Desde a época do Movimento Municipalista catarinense, um dos mais antigos do país, iniciado por volta dos anos 1960, a busca por maior poder decisório dos municípios e por assessoramento em questões técnico-administrativa tem-se dado por meio destas associações. Na década de 1980, o associativismo municipal no Estado contava com 15 associações, abrangendo todo o território. A partir deste movimento, foi criada a Federação Catarinense de Municípios [FECAM]. Atualmente ela conta com 284 municípios filiados dos 293 municípios de SC (FECAM, 2008 [Recuperado em 21 de fevereiro de 2008, de http://www.fecam.org.br/home/index.php]). Foram as associações de municípios, coordenadas pela FECAM, que deram o impulso para a criação dos fóruns de desenvolvimento em cada uma de suas áreas territoriais (Côrtes, 2006).

A criação dos fóruns de desenvolvimento regional foi motivada pelas limitações históricas do governo central de SC em atender o interior do Estado e pela necessidade, percebida pelos seus protagonistas, do envolvimento de diferentes atores na co-produção do desenvolvimento regional. A experiência dos Fóruns de Desenvolvimento Regional Integrado de Santa Catarina [FDRI], que teve início em 1996 no Oeste Catarinense, na cidade de Chapecó, disseminou-se por todo Estado. Estes fóruns foram criados como instituições, congregando organizações de Estado, da sociedade civil e do mercado (Rover, 2007). O desenvolvimento das atividades dos fóruns regionais gerou a necessidade da criação de um mecanismo que desse suporte operacional para a execução das ações demandadas por eles, denominado: Agência de Desenvolvimento Regional [ADR]. Essas agências foram inspiradas nas ADRs européias e buscavam ser plataforma técnico-institucional de caráter operativo, que identificavam os problemas de desenvolvimento setorial ou regional.

\section{Características da Descentralização em SC}

Além das associações dos municípios, nascidas da iniciativa dos prefeitos, dos fóruns e das agências de desenvolvimento regional, de iniciativa da sociedade civil, outra forma de organização regional foi conduzida e implantada no Estado de Santa Catarina, dessa vez por iniciativa do governo do Estado. Trata-se da implantação, por Lei, em 2003, das Secretarias de Desenvolvimento Regionais [SDRs]. Por meio desta ação, o governador construiu uma forte rede político-partidária que lhe permitiu aprovar as Leis que garantiram a Reforma Administrativa em SC e consolidar um projeto político de ampliação do poderio do Executivo. 
A idéia da criação das SDRs pela equipe do governador Luiz Henrique da Silveira foi inspirada nos modelos europeus e na própria experiência do governador: "nós utilizamos as experiências e o conhecimento de alguns experts italianos sobre os distritos industriais e de estudiosos brasileiros sobre a questão da descentralização” (E1). A Reforma Administrativa do Estado de Santa Catarina, nominada por seus protagonistas de "descentralização do governo e regionalização do desenvolvimento", dividiu a estrutura do governo em dois níveis: Setorial que compreende as Secretarias Setoriais (centrais), tendo o papel de normatizar, formular e controlar as políticas públicas; e Regional (as SDRs) com o objetivo de coordenar e executar as políticas públicas.

Tabela 3

\section{Reformas Administrativas em SC (2003/2007) e Ordenamento legal das SDRs}

\begin{tabular}{|c|c|c|c|}
\hline Data & Lei & Objetivo & $\begin{array}{c}\text { N. SDRs } \\
\text { criadas }\end{array}$ \\
\hline $30 / 1 / 2003$ & LCP- 000243 & $\begin{array}{l}\text { Estabelecer nova Estrutura Administrativa do Poder Executivo, } \\
\text { implantação, descentralização e regionalização da estrutura } \\
\text { administrativa. A execução das atividades da administração } \\
\text { estadual será descentralizada e desconcentrada e se dará } \\
\text { preponderantemente pelas SDRs. }\end{array}$ & 29 SDRs \\
\hline 28/2/2005 & LCP- 000284 & $\begin{array}{l}\text { Estabelecer um modelo de gestão para a administração pública } \\
\text { estadual estrutura organizacional do poder executivo e reforma } \\
\text { administrativa. }\end{array}$ & 30 SDRs \\
\hline 7/5/2007 & LCP- 000381 & $\begin{array}{l}\text { Estabelecer reforma administrativa na administração pública } \\
\text { estadual em sua estrutura organizacional, secretaria executiva de } \\
\text { gestão dos fundos estaduais. }\end{array}$ & 36 SDRs \\
\hline
\end{tabular}

Nota. Fonte: Procuradoria Geral do Estado de Santa Catarina. (2003). Lei complementar $n^{\circ} 000243$, de 30 de janeiro de 2003. Recuperado em 20 fevereiro, 2008, de http://server03.pge.sc.gov.br/legislacaoestadual/2003/000243-010-0-2003001.htm, Procuradoria Geral do Estado de Santa Catarina. (2005). Lei complementar $n^{\circ} 000284$, de 28 de fevereiro de 2005. Recuperado em 20 fevereiro, 2008, de http://server03.pge.sc.gov.br/legislacaoestadual/2005/000284-010-0-2005-002.htm, Procuradoria Geral do Estado de Santa Catarina. (2007). Lei complementar $n^{\circ}$ 000381, de 07 de maio de 2007. Recuperado em 20 fevereiro, 2008, de http://server03.pge.sc.gov.br/legislacaoestadual/2007/000381-010-0-2007-001.htm

A sugestão da Fecam para a equipe do governador Luiz Henrique, eleito em 2002, era pela compatibilização da área geográfica das SDRs com a das 21 associações de municípios (a mesma dos fóruns/agências). Contudo foram criadas 29 SDRs em 2003; a partir de 2005 o número de secretarias foi aumentado para 30 e em 2007 para as atuais 36 SDRs. Apesar de uma visão que buscava, em tese, favorecer a autonomia regional, aparentemente o governo do Estado não considerou a experiência anterior de cooperação regional dos Fóruns/agências de desenvolvimento nem a sugestão da Fecam. O governo catarinense, ao observar a mobilização associativista pelo desenvolvimento regional de base territorial no Estado, não quis ficar sem as vantagens deste tipo de iniciativa. Ao propor o modelo das SDRs em substituição ao dos Fóruns, o governo estadual procura capitalizar, pela variável de ocupação partidária dos cargos das SDRs, o efeito político resultante desta estratégia de descentralização e regionalização. Em grande medida, a classe política hegemônica em termos partidários procurou controlar, no sentido de favorecer certa previsibilidade, o processo de articulação regional conduzido antes majoritariamente pela sociedade civil. 
Tabela 4

\section{Caracterização dos FDR e das SDRs}

\begin{tabular}{|c|c|c|}
\hline Característica & Fóruns de Desenvolvimento Regional & Secretarias de Desenvolvimento Regionais \\
\hline $\begin{array}{l}\text { Momento } \\
\text { constituição }\end{array}$ & $\begin{array}{l}\text { Anos } 1990 \text { pela iniciativa das } \\
\text { Associações de Municípios e da Fecam. }\end{array}$ & 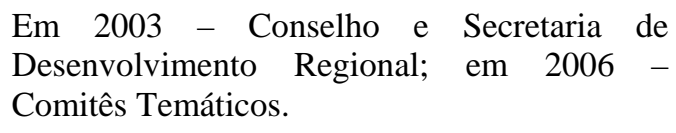 \\
\hline $\begin{array}{l}\text { Princípios } \\
\text { orientadores }\end{array}$ & $\begin{array}{l}\text { Integração das ações das instituições } \\
\text { públicas e privadas que representam as } \\
\text { organizações sociais e econômicas para } \\
\text { o planejamento e a execução das ações } \\
\text { estratégicas para desenvolvimento. }\end{array}$ & $\begin{array}{l}\text { Fortalecimento das entidades locais e da } \\
\text { sociedade; organizar e mobilizar capital humano } \\
\text { em uma estratégia de desenvolvimento; } \\
\text { participação dos agentes de desenvolvimento em } \\
\text { todas as etapas do planejamento participativo; }\end{array}$ \\
\hline Objetivos & $\begin{array}{l}\text { Integrar as entidades envolvidas com o } \\
\text { desenvolvimento para viabilizar um } \\
\text { Plano Catarinense de Desenvolvimento, } \\
\text { que assegure a continuidade dos } \\
\text { Programas e Projetos em implantação. }\end{array}$ & $\begin{array}{l}\text { Regionalização do desenvolvimento; } \\
\text { modernização da gestão pública; inclusão } \\
\text { social; desenvolvimento econômico; melhoria } \\
\text { na qualidade de vida; desenvolvimento } \\
\text { ambiental. }\end{array}$ \\
\hline Composição & $\begin{array}{l}\text { Prefeitos da região de abrangência de cada } \\
\text { Fórum; representantes de entidades: } \\
\text { universidades, sindicatos, entidades de } \\
\text { classe, associações comerciais/industriais, } \\
\text { igrejas, movimentos sociais, entre outros. }\end{array}$ & 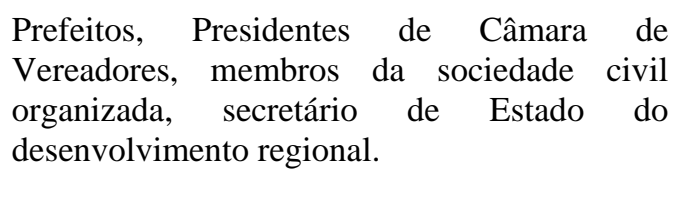 \\
\hline Intervalo/reuniões & Mensal. & CDR: reunião ordinária mensal. \\
\hline Perfil político & Sem identificação partidária explícita. & $\begin{array}{l}\text { Filiados aos partidos da coligação que governa } \\
\text { SC (PMDB/DEM/PSDB). }\end{array}$ \\
\hline
\end{tabular}

Fonte: elaborado a partir de Rover, O. J. (2007). Redes de poder e governança local: análise da gestão políticoadministrativa em três fóruns de desenvolvimento com atuação na região Oeste de Santa Catarina/Brasil (pp. 155-157). Tese de doutorado, Universidade Federal do Rio Grande do Sul, Porto Alegre, RS, Brasil.

Alguns entrevistados foram enfáticos ao afirmar a existência de certos conflitos na relação governo/sociedade civil, expressa na relação entre fóruns/agências e SDRs: "Não existiu transição entre fóruns para SDRs! São entes ciumentos entre si. Só há ações diferenciadas. Não existe a integração.” (E3). Além deste fator, há os que percebem ações justapostas entre os fóruns/agência e as SDRs: "Eu acho que ficou meio paralelo." (E4).

Já o entrevistado (E6), parece perceber um forte papel das SDRs em relação ao Desenvolvimento Regional, até mesmo atribuindo a elas o surgimento do próprio desenvolvimento em SC, talvez por desconhecer as experiências anteriores de articulação territorial: "O desenvolvimento regional começou a surgir depois que foram criadas as secretarias de desenvolvimento regional”. Observa-se que o desconhecimento da existência de fóruns/agências, anteriores às SDRs, aponta uma descontinuidade entre a proposta dos fóruns/agências e a das SDRs, pelo menos do ponto de vista daqueles que são gestores dentro das SDRs, como é o caso deste entrevistado.

A visão de que as SDRS têm apenas uma conotação político-partidária é compartilhada pela maioria dos entrevistados originários de fóruns/agências; este grupo de entrevistados é o que mais reforça a idéia de ruptura entre fóruns/agências e SDRs: "Eu não vejo caracterização nenhuma de transição, e sim o que houve foi um corte abrupto na existência dos fóruns e da própria agência, vindo, em seus lugares, as SDRs” (E16). Esta visão de que uma estrutura fez sombra à outra, também é percebida pelo entrevistado E18, quando declara sua visão de como a sociedade reage negativamente à tomada do comando da regionalização do desenvolvimento pelo governo em Santa Catarina: "Bah! Pensam assim: se o governo está fazendo, então eu não preciso fazer! Então, de certa forma ela (a SDR) ofuscou (os fóruns/agências) e também, ofuscou muito as associações de município." 
Outro aspecto que parece relevante é a falta de conhecimento/compreensão dos gestores das SDRs acerca da atuação dos fóruns/agências, de acordo com visão do entrevistado, membro de uma SDR. "A questão é a seguinte: a secretaria regional, e quando falo em secretaria regional é do seu executivo máximo (o Secretário), jamais entendeu qual a vantagem da agência de desenvolvimento; a vantagem competitiva e a sinergia que ela poderia trazer para o desenvolvimento regional” (E19). As diferenças entre fóruns/agências parecem ser mais visíveis aos entrevistados do que as similitudes: "a postura das SDRs é completamente diferente da postura dos fóruns/agências. Por terem (as SDRs) uma conotação política. Há a ausência da participação popular no processo das SDRs; nelas participam apenas pessoas indicadas" (E18). Neste caso, o objetivo da descentralização, apontado pela literatura de aproximar governo e cidadão, parece ficar fragilizado. Observa-se que os benefícios políticos de oferecer serviços públicos regionalizados representam um poderoso incentivo à aceitação do processo de descentralização (Arretche, 1996) e o governo catarinense parece ter percebido estas vantagens. A possibilidade, descortinada pela implantação das SDRs, de determinar na região, sem depender de Florianópolis, quais serviços de infra-estrutura são realizados, anima os distribuidores destes serviços, pois percebem uma compensação eleitoral bastante promissora. A passagem dos fóruns para as SDR ao mesmo tempo que leva a supor uma cooptação, pelo governo, desta estrutura associativista presente nas regiões catarinenses, instiga o seu contraditório: por que motivo os membros dos fóruns e das agências não se opuseram a esta estratégia governista de controle?

Outro aspecto a ser observado é uma discrepância observada entre a visão de descentralização daqueles que têm sido os mentores da descentralização em SC e a sua implementação prática, a qual, pela análise dos dados colhidos nas entrevistas, aponta uma prática fortemente absorvida por um jogo político que faz com que a articulação regional seja instrumento político-eleitoral. O processo descentralizado em Santa Catarina é percebido pelos seus mentores (intelectuais que assessoram o governador) como "o acesso das pessoas à cidadania; o processo de empoderamento, onde elas entendem qual é o seu papel cidadão” (E1).

Quando perguntados se em Santa Catarina há um processo efetivo de descentralização, os entrevistados alinhados ao governo respondem afirmativamente: "Santa Catarina vem desenvolvendo um processo de descentralização desde o ano de 2003, quando se criaram as SDRs; desta forma, o governo do Estado descentralizou as decisões que passaram a ser discutidas nas regiões por meio dos Conselhos de Desenvolvimento Regional” (E10). Para um dos representantes da Fecam a descentralização ocorre em parte, já que a "existência das secretarias nas regiões sugere a descentralização; no entanto os recursos efetivamente não estão descentralizados, dependendo sempre de uma decisão de secretaria central ou do governador" (E12). É possível que o tempo curto de implantação desta experiência ainda não permita vislumbrar todos os seus efeitos descentralizantes. Mais enfático em negar a descentralização, o E5, da oposição, afirma que "não existe um processo de descentralização, porque os recursos orçamentários estão cada vez mais concentrados na pessoa do governador, inclusive criando uma conta que dá liberdade ao governador de liberar recursos ao seu bel prazer". Esta observação sugere que o conceito de descentralização possa estar sendo usado em Santa Catarina com fins de legitimação do poder hegemônico da coalizão que está no governo.

\section{Coalizões Político-eleitorais}

Santa Catarina tem uma história política na qual as oligarquias sempre estiveram presentes. A parir de meados dos anos oitenta, a influência das oligarquias diminuiu. Desde então, alternam-se no governo coalizões partidárias de centro-direita, lideradas por políticos do PFL ou PPB (hoje PP) e de centro-esquerda, liderados pelo PMDB (Côrtes, 2006). Tem havido uma alternância entre, de um lado, governadores eleitos por PDS (PPB - hoje PP) ou PFL (atual DEM) e, de outro, o PMDB. Os dois governos de Luiz Henrique da Silveira foram eleitos por meio de ampla coalizão partidária liderada pelo PMDB, o que se observa na Tabela 5. O Partido dos Trabalhadores apoiou o governo estadual até o final de 2004, quando passou a ser oposição ao governo (E8). A estratégia das coligações foi acirrada para o segundo turno das eleições de 2006, permitindo dar legitimidade à Reforma Administrativa. 
Tabela 5

\section{Candidaturas às Eleições para Governador SC 2006 no $2^{\circ}$ Turno}

\begin{tabular}{llll}
\hline Ano & \multicolumn{1}{c}{ Candidatos } & \multicolumn{1}{c}{ Coligações } & Votos 2 ${ }^{\circ}$ Turno \\
\hline \multirow{2}{*}{2006} & Luiz Henrique da Silveira & PMDB/PFL/PSDB/PPS/PRTB/PC do B/PAN/PHS & 1.685 .184 \\
& Esperidião Amin Helou Filho & PP/PMN/PV/PRONA & 1.511 .916 \\
\multirow{2}{*}{ TOTAL } & & $\mathbf{3 . 1 9 7 . 1 0 0}$ \\
\hline
\end{tabular}

Nota. Fonte: Tribunal Regional Eleitoral. (2006). Eleições 2006: divulgação de resultados. Recuperado em 21 fevereiro, 2008, de http://www.tre-sc.gov.br/site/fileadmin/arquivos/eleicoes/eleicoes2006/weblogs/resultado/2turno/estadual.html\#governador

Somente com esta ampla formação de coligação partidária foi possível ao candidato Luiz Henrique derrotar Esperidião Amin e levar adiante o projeto de implantação das SDRs que criara no seu primeiro mandato. Viu-se, no período eleitoral, uma intensa movimentação dos membros das SDRs em torno da reeleição de Luiz Henrique e da continuidade do que denominam de descentralização em SC. Além da continuidade do processo, ao reassumir o governo, Luiz Henrique ampliou a fragmentação da abrangência das SDRs passando de 30 para 36, por meio da Lei complementar n. 381. A ampliação do número das SDRs implicou a diminuição do número de municípios constituintes de cada uma delas e atendeu a critérios não revelados à sociedade. Há indícios de que eles tenham obedecido a interesses de lideranças regionais que dão sustentação ao governo, tornando-se o grande pacto de sustentação do segundo mandato. O que se pode inferir é que em Santa Catarina a descentralização é também sinônimo de regionalização política.

Os Secretários de Estado do Desenvolvimento Regional são nomeados pelo governador, obedecendo a critérios de indicação pelos partidos da coalizão política que governa SC e aos interesses destes grupos em cada região. Neste sentido, ocorre apoio eleitoral recíproco: "a lista de candidatos que competem nas eleições locais pode ser escolhida pelos dirigentes do partido no governo central; em contrapartida, as autoridades locais podem desempenhar um papel-chave na seleção dos candidatos para as eleições governamentais do governo central” (Rodden, 2005, p. 16). Na maioria das SDRs observou-se intensa disputa, difundida pelos meios de comunicação, para a indicação, não somente para o cargo de Secretário, como também para as diretorias e gerências dentro das SDRs.

Ao analisar a variável da carreira político-partidária dos Secretários indicados pelo governador, observa-se que dos 36 Secretários, 24 são filiados ao PMDB, 7 são filiados ao PSDB e 5 são filiados ao DEM (antigo PFL), justamente os partidos da coalizão dominante (Tabela 4). Quanto à atuação político-administrativa, dentre os SDRs, 12 foram prefeitos; 3 vice-prefeitos; 8 vereadores; 3 deputados estaduais/federais; 8 exerceram cargos comissionados (secretário municipal/estadual/presidente de autarquia) e apenas 2 vieram da iniciativa privada. Dos 36 SDRs, 11 se licenciaram para concorrer às eleições de 2008; 9 serão candidatos a prefeito - 7 do PMDB e 2 do PSDB - e 2 a vice-prefeito - 1 do DEM e 1 do PMDB (Tribunal Superior Eleitoral [TSE], 2006).

A atuação do governo do Estado, neste processo de articulação regional, é percebida de diferentes formas, dependendo do lugar político-partidário de onde fala o entrevistado. Para entrevistado situacionista, "a atuação do governo do Estado tem sido providencial para o desenvolvimento das regiões em SC. A preocupação do governador em transmitir o poder de decisão para os municípios tem alcançado resultados positivos” (E10). De fato os prefeitos têm-se pronunciado publicamente favoráveis à aproximação do governo nas regiões por meio das SDRs. A influência de interesses políticos locais, sobre a tomada de decisão do governo do Estado foi assinalada por outros entrevistados, até mesmo aqueles pertencentes aos quadros das SDRs. Segundo o entrevistado (E5), as SDRs funcionam como uma "forte estrutura político-partidária, pois os cargos são de livre nomeação, ou seja, cargos de confiança indicados pelos partidos que compõem a base do governo, equacionando assim o problema de compra das decisões políticas e uma estrutura de apoio de cabos eleitorais”. 
Contudo a tentativa do governo estadual de se aproximar das regiões parece estar sendo alcançada. O entrevistado E13 ressalta que "o governo não fica mais só na capital, ele fica em cada uma das microrregiões.” Os entrevistados membros das SDRs declararam que a atuação do governo de SC em relação à descentralização se dá por meio deste elenco: repasse de recursos; capacitação; cedência de servidores e repasse de informações. Para o E5, no entanto, esta atuação do governo "incita a competição predatória, a sobreposição de funções, capitalizando ações de outrem, buscando desestruturar outras organizações instituídas há várias décadas.” Percebe-se ainda que a proliferação de SDRs, desde 2003 até 2007, faz parecer que há uma ampliação da base de poder da coalizão partidária dominante em Santa Catarina, arquitetada pelo governador Luiz Henrique, e não necessariamente uma democratização requerida pela descentralização. No caso das SDRs, as suas estruturas operacionais são compostas por pessoas vinculadas aos partidos da base governista e o número de cargos remunerados ocupados varia entre quinze e trinta (Birkner, 2005).

\section{Resultados Percebidos}

Quanto aos resultados dos fóruns/agências e aos resultados das SDRs, os mais citados pelos entrevistados estão elencados na Tabela 6.

Tabela 6

\section{Resultados de Fóruns/Agências e SDRs}

\begin{tabular}{ll}
\hline \multicolumn{1}{c}{ Fóruns/agências } & \multicolumn{1}{c}{ SDRs } \\
\hline - Busca conjunta de recursos em fontes externas (8 & - Facilitar o andamento de e obras especialmente \\
citações); & reforma de escolas (6 citações); \\
- Elaboração de projetos regionais (12 citações); & - Criou uma burocracia (2 citações); \\
- Ações estruturantes na área de infra-estrutura (ex. & - não tenho conhecimento (dos resultados da SDR) \\
aeroporto regional; centro tecnológico) (5 & (3 citações); \\
citações); & - Melhorou a relação da região com o governo (2 \\
- A participação da comunidade nas decisões & citações); \\
acerca do desenvolvimento (6 citações). & - Democratização na tomada de decisão (1 citação). \\
\hline
\end{tabular}

Nota. Fonte: dados da pesquisa.

Observa-se que os principais resultados apontados para os fóruns/agências assinalam a elaboração e encaminhamento de projetos conjuntos, enquanto os resultados das SDRs são percebidos, na sua maioria, no setor de obras. Entretanto, "A existência de programas - ou a disposição do nível de governo interessado - é uma condição necessária, mas não suficiente para que ocorra descentralização" (Arretche, 1999, p. 9). Os entrevistados citam, como resultados objetivos das SDRs, a construção de centros de eventos e ginásios de esportes; a pavimentação de estradas; as reformas de escolas; a destinação de recursos para hospitais e para a realização de eventos: feiras, exposições etc. Salienta-se que estes serviços públicos são os mesmos que recebiam atenção dos governos antes da descentralização de 2003. A superação, via SDRs, da distância da capital do Estado em relação às regiões, antigo motivo de descontentamentos regionais, é apontada como resultado positivo da reforma administrativa: "Há algum tempo os prefeitos do interior precisavam viajar quase $500 \mathrm{~km}$ para apresentar um projeto ao governo do Estado; hoje isso não é mais necessário.” (E10). Outros entrevistados entendem que o processo de descentralização aumentou a possibilidade de participação das regiões: "veio a descentralização, foram criadas as regionais para que as regiões pudessem decidir" (E14).

Num estudo comparativo, Goulart (2007) argumenta que, em 2004, para manter 29 SDRs, somente em custeio, foi feita uma despesa de R\$ 72,2 milhões. Em 2006, a despesa de custeio das 30 SDRs subiu para R\$ 136,6 milhões, o que dá uma variação de 89,03\%. Analisando a evolução da Receita Tributária no período 2004/2006, Goulart (2007) aponta que ela não acompanhou o crescimento do 
custeio das SDRs: no período 2004 a 2006 o crescimento da Receita Tributária foi 67,08\% a menos que o custeio das SDRs.

Em termos de orçamento, é difícil precisar qual é o poder decisório das SDRs sobre o orçamento pertinente à sua região de abrangência. O desenho atual da participação das SDRs no orçamento é o seguinte: o Conselho de Desenvolvimento Regional [CDR] levanta as necessidades regionais. Destas necessidades levantadas, o CDR define prioridades que são encaminhadas ao governo estadual que as contempla (ou não) no orçamento.

Observa-se que aumentou o custo da estrutura, não necessariamente o investimento nas regiões e, sobretudo, não houve reforço do seu poder decisório. Além destes fatores, a percepção comum dos entrevistados de que entre os resultados das SDRs estão apenas custos com a burocracia e em áreas de investimento compulsório, como a educação, é confirmado pelos dados apresentados pelo TCE/SC: "Educação e administração foram os itens que consumiram a maior parte dos recursos das secretarias." (Tribunal de Contas de Santa Catarina, 2005, p. 81).

O PPA da região é montado por toda a estrutura de governo em cada região, ou seja, pelos gerentes das SDRs, gerentes de autarquias, gerentes das setoriais presentes nas regiões (E26). As SDRs podem decidir sobre aplicação de despesas fixas: aluguel, pessoal, manutenção etc. Em relação a investimentos, podem decidir apenas dentro de percentual orçamentário definido pelo governo estadual e obedecendo às fontes de recursos pré-estipuladas. Como afirma Rodden (2005, p. 13), "a descentralização do gasto governamental pode dizer muito sobre o lócus da autoridade”; contudo, em Santa Catarina, ainda é difícil precisar o poder decisório das regiões sobre a elaboração e aplicação do orçamento.

\section{A Participação Social}

Em relação à participação da sociedade civil nas SDRs, o entrevistado situacionista assim fala (E10): “com a descentralização, a sociedade sente um maior poder de opinião.” Observa-se que com a criação das SDRs hoje, em SC, existe um espaço para os prefeitos conversarem diretamente com o governador, sem necessidade da intervenção de um parlamentar. O espaço das SDRs permite a regionalização dos pleitos dos prefeitos, aproximando governo do Estado e municipalidades. Já para um entrevistado de oposição, "há uma participação de cartas marcadas" (E5), ressaltando que os prefeitos situacionistas levam vantagem. Considerando que participação e controle social são apontados pela literatura como elementos-chave a um processo de descentralização, cabe a reflexão acerca de como esta participação social está desenhada na Reforma Administrativa em Santa Catarina.

Um dos mecanismos previsto na Reforma Administrativa é a implantação dos Conselhos de Desenvolvimento Regional, os CDRs existentes em cada SDR. Segundo a Lei Complementar $n^{\circ}$ 284/2005 (Procuradoria Geral do Estado de Santa Catarina, 2005), o CDR é formado pelos Prefeitos Municipais, Presidentes das Câmaras Municipais, dois representantes por município de entidades civis organizadas, sendo presidida pelo Secretário de Estado do Desenvolvimento Regional. Os Conselhos são órgãos de aconselhamento, orientação, formulação (das normas) e proposição das diretrizes gerais para o desenvolvimento das atividades das Secretarias.

Foram entrevistados, escolhidos de forma aleatória por esta pesquisa, os conselheiros de uma das 36 SDRs, representantes da sociedade civil. Os entrevistados preocupam-se com o rumo localista que as decisões do seu CDR estão tomando. Ademais, eles têm a visão de que o CDR é palco das disputas dos municípios. Os conselheiros entrevistados também se ressentem da aparente ineficácia do CDR, devido à questão de indisponibilidade de recursos e alguns deixam de participar das reuniões. Fleury (2006) enfatiza que na descentralização o controle social pode ser exercido por meio de conselhos, existentes em cada um dos níveis governamentais, nos quais é assegurada a participação equilibrada do governo e da sociedade civil. Aparentemente, o Conselho de Desenvolvimento Regional [CDR] existente nas SDRs ainda não pode ser entendido na extensão de controle social que atribui Fleury aos conselhos. Enquanto nos fóruns/agências a participação das redes público-privadas são percebidas, nas 
SDRs são apontados os membros da própria burocracia estatal como protagonistas no processo decisório.

\section{CONSIDERAÇÕES FINAIS}

Santa Catarina tem marcada tradição associativista, bons índices de desenvolvimento humano e econômico, mas mantém fortes disparidades regionais. Tais desigualdades geraram, por um lado, a mobilização de atores regionais em busca de projetos de desenvolvimento e, por outro, sucessivas propostas de planificação do desenvolvimento para o Estado. Destas iniciativas públicas ou privadas tem-se construído um quadro de efervescentes articulações de base territorial que, por vezes, se entrechocam no território catarinense. $\mathrm{O}$ fenômeno estudado neste artigo analisou a reversão, nesta unidade federativa, de uma experiência originária de redes de cooperação regional, para outra comandada pelo governo estadual. Se, por um lado, esta atuação do governo de SC se pauta por um ideário de descentralização para o desenvolvimento e de governo mais próximo do cidadão, por outro, na prática, o que a sociedade ainda percebe é uma estratégia político-partidária de poder. Os interesses específicos de lideranças regionais tiveram, na criação das SDRs, um reforço e, em contrapartida, oferecem amplo apoio à proposta do governador de regionalizar a administração pública.

Enquanto a delegação de funções administrativas e a coordenação de instâncias de governo em nível se local vêm demonstrando muito aplicada, a autonomia compartilhada e o acesso ao poder decisório pelas regiões estão ainda longe de se concretizar. Os mecanismos de participação e de controle por parte da sociedade civil ainda precisam ser reforçados, especialmente na formação, adequação e atribuições dos Conselhos de Desenvolvimento regional. Os resultados mais visíveis da implantação das SDRs são as obras de infra-estrutura, algo não muito distante das tradicionais ações de governos anteriores. A novidade é que desde 2003 as regiões podem, minimamente, opinar sobre a prioridade desta ou daquela obra a ser realizada na sua região. Há desconfiança, por parte daqueles que atuavam nas redes de articulação regionais (fóruns e associações de municípios), de que a descentralização em curso não passe de um estratagema para ampliação e manutenção no poder do que hoje é chamada de Tríplice Aliança (PMDB, PSDB e DEM). Isso fica mais evidente, sabendo que a regionalização constituiu a liga que uniu mais fortemente tais partidos no segundo mandato do governador Luiz Henrique.

Embora a literatura aponte que em contextos onde há tradição associativista estratégias de descentralização sejam mais favorecidas, em Santa Catarina houve uma reversão do processo. O que os resultados da pesquisa revelam é que a concentração de poder em SC passa pelo controle da máquina política posta em ação pela estrutura de sustentação da coalizão dominante nas SDRs. Contudo é inegável que o debate crítico desta experiência e as constantes renegociações na arena política podem contribuir para o aperfeiçoamento, seja de seu sistema de funcionamento, seja da retomada de seus princípios de descentralização para o desenvolvimento, resguardando a autonomia e a interdependência. A experiência ainda é muito recente e talvez ainda não chegue a ponto de modificar profundamente relações arraigadas de clientelismo e patrimonialismo tão cristalizadas nas relações políticas brasileiras.

É possível que a criação de mecanismos e instâncias que equilibrem os interesses do governo estadual, dos municípios e da sociedade civil possam mudar o sentido mais desconcentrador do que descentralizador da experiência catarinense atual. Para tanto é necessário melhorar significativamente o modelo institucional adotado, diminuindo a influência partidária na indicação dos principais cargos de comando da regionalização, além de fortalecer os instrumentos de accountability, para viabilizar o efetivo exercício da cidadania nos planos local e regional.

Artigo recebido em 28.10.2008. Aprovado em 11.03.2009. 


\section{REFERÊNCIAS BIBLIOGRÁFICAS}

Abrucio, F. L., \& Soares, M. M. (2001). Redes Federativas no Brasil: cooperação intermunicipal no grande ABC. São Paulo: CEDEC, Fundação Konrad Adenauer, Oficina Municipal.

Arretche, M. (1996). Mitos da descentralização: mais democracia e eficiência nas políticas pública? Revista Brasileira de Ciências Sociais, 11(31), 44-66.

Arretche, M. (1999). Políticas sociais no Brasil: descentralização em um estado federativo. Revista Brasileira de Ciências Sociais, 14(40), 111-141.

Arretche, M. (2000). Estado Federativo e políticas sociais: determinantes da descentralização. Rio de Janeiro: Revan.

Becattini, G. (2002). Os distritos industriais na Itália. In A. Urani, G. Cocco, \& A. P. Galvão (Orgs.), Empresários e empregos nos novos territórios produtivos: o caso da terceira Itália. Rio de Janeiro: DP\&A.

Birkner, W. M. K. (2005). Intervenções governamentais nos processos decisórios para a promoção do desenvolvimento regional: um estudo de caso das secretarias de desenvolvimento. Revista REDES, 10(2), 61-78.

Birkner, W. M. K. (2006). Capital social em Santa Catarina: o caso dos fóruns de desenvolvimento regional. Blumenau: FURB.

Côrtes, S. V. (2006). Instituições e ação estatal: coordenação nos governos estaduais catarinense e gaúcho - 2003/2006. In C. Souza \& P. F. Dantas Neto (Orgs.), Governo, políticas públicas e elites políticas nos estados brasileiros (Vol. 1). Rio de Janeiro: Revan.

Diba, D. R. (2004). Regiões metropolitanas paulistas e cooperação intergovernamental: um estudo comparativo. Dissertação de mestrado, Fundação Getúlio Vargas, São Paulo, SP, Brasil.

Farah, M. F. S. (2001). Parcerias, novos arranjos institucionais e políticas públicas no nível local de governo. Revista de Administração Pública, 35(1), 119-144.

Fleury, S. (2006). Democracia, descentralização e desenvolvimento: Brasil e Espanha. Rio de Janeiro: FGV.

Goulart, J. G. (2007). O mito do desenvolvimento regional em Santa Catarina [Mensagem Pessoal]. Assessoria coletiva da bancada do PT, recebido por e-mail em 17 de agosto de 2007.

Hering, M. L. R. (1987). Colonização e indústria no Vale do Itajaí: o modelo catarinense de desenvolvimento. Blumenau: FURB.

Procuradoria Geral do Estado de Santa Catarina. (2003). Lei complementar $n^{\circ}$ 000243, de 30 de janeiro de 2003. Recuperado em 20 fevereiro, 2008, de http://server03.pge.sc.gov.br/legislacaoestadual/2003/000243-010-0-2003-001.htm

Procuradoria Geral do Estado de Santa Catarina. (2005). Lei complementar $n^{o}$ 000284, de 28 de fevereiro de 2005. Recuperado em 20 fevereiro, 2008, de http://server03.pge.sc.gov.br/legislacaoestadual/2005/000284-010-0-2005-002.htm

Procuradoria Geral do Estado de Santa Catarina. (2007). Lei complementar $n^{\circ} 000381$, de 07 de maio de 2007. Recuperado em 20 fevereiro, 2008, de http://server03.pge.sc.gov.br/legislacaoestadual/2007/000381-010-0-2007-001.htm 
Rodden, J. (2005). Federalismo e descentralização em perspectiva comparada: sobre significados e medidas. Revista Sociologia Política, (24), 9-27. Recuperado em 23 setembro, 2005, de http://www.scielo.br/pdf/rsocp/n24/a03n24.pdf

Rover, O. J. (2007). Redes de poder e governança local: análise da gestão político-administrativa em três fóruns de desenvolvimento com atuação na região Oeste de Santa Catarina/Brasil. Tese de doutorado, Universidade Federal do Rio Grande do Sul, Porto Alegre, RS, Brasil.

Souza, C. (1998). Intermediação de interesses regionais no Brasil: o impacto do federalismo e da descentralização. Dados 41(3), 1-21. Recuperado em 24 abril, 2007, de http://www.scielo.br/scielo.php?pid=S0011-52581998000300003\&script=sci_arttext\&tlng=en

Tendler, J. (1998). Bom governo nos trópicos: uma visão crítica. Rio de Janeiro: Revan.

Tobar, F. (1991). O conceito de descentralização: usos e abusos. Planejamento e Políticas Públicas, (5), 31-51.

Tribunal de Contas de Santa Catarina. (2005). Para onde vai o seu dinheiro [Edição 2005]. $\begin{array}{lllll}\text { Recuperado em } & 20 & \text { fevereiro, }\end{array}$ http://www.tce.sc.gov.br/site/publicacoes/livros/pdf/tce_04.pdf

Tribunal Regional Eleitoral. (2006). Eleições 2006: divulgação de resultados. Recuperado em 21 fevereiro, 2008, de http:/www.tresc.gov.br/site/fileadmin/arquivos/eleicoes/eleicoes2006/weblogs/resultado/2turno/estadual.html \#governador

Tribunal Superior Eleitoral. (2006). Resultado das Eleições de 2006. Recuperado em 21 julho, 2008, de http://www.tse.gov.br/internet/eleicoes/resultado_2006.htm

Yin, R. K. (2001). Estudo de caso: planejamento e métodos (2a ed.). (D. Grassi, Trad.). Porto Alegre: Bookman. (Obra original publicada em 1984).zl 